\title{
Does Entitlement Card ensure Utilization of Urban Primary Healthcare Clinic in Bangladesh?
}

\author{
Sharmin Mizan'), Md Mizanur Rahman'), Razitasham Safii'), Sk Akhtar Ahmad) \\ 1)Faculty of Medicine and Health Sciences, Universiti Malaysia Sarawak, Malaysia \\ 2)Faculty of Public Health, Bangladesh University of Health Sciences, Dhaka, Bangladesh
}

\section{ABSTRACT}

Background: Although Bangladesh substantially reduced $40 \%$ maternal death in the last decades, it is still challenging, especially among the urban poor. The achievements are not equitable between different economic quintiles and between the rich and the urban poor. This study aims to examine the extent to which the entitlement card affects the utilization of maternal and child health care and identifies other factors that influence MCH services.

Subjects and Method: This cross-sectional study was carried out in the working areas of the Urban Primary Healthcare Project (UPHCP) in Bangladesh. A two-stage cluster sampling technique was used to select the participants. A total of 3,949 women aged 15-49 years, having at least one child aged two years or less were selected for this study. The data were collected through faceto-face interviews. The data were analyzed using multinomial logistic regression.

Results: The proportion of utilization of UPHCC was $49.9 \%$. One-fourth $(26.6 \%)$ of them fully utilized it and another $23.3 \%$ utilized it partially. Stepwise multinomial logistic regression analysis revealed that those who had an Entitlement Card from the UPHC project were 11.75 times (95\% $\mathrm{CI}=9.481,14.549 ; \mathrm{p}=0.001)$ more likely to fully Utilized and 3.64 times $(95 \% \mathrm{CI}=3.643,2.911$; $\mathrm{p}=0.001$ ) likely be utilized partially compared to non-utilizer. Respondents having no formal education utilized UPHCC fully $(\mathrm{AOR}=2.32 ; 95 \% \mathrm{CI}=$ $1.46,3.68 ; \mathrm{p}=0.001)$ and partially $(\mathrm{AOR}=1.76$; 95\% $\mathrm{CI}=1.12,2.77 ; \mathrm{p}=0.014)$ used UPHCC. It was $3.08(95 \% \mathrm{CI}=2.03,4.67 ; \mathrm{p}=0.001)$ times for fully and $2.71(95 \% \mathrm{CI}=1.82,4.04 ; \mathrm{p}=0.001)$ times for partially utilized UPHCC compared to non-users among the primary level of education. Small family size $(\leq 4)$ and monthly family income in the range of BDT 10,000 above were likely to utilise UPHCC. However, non-Muslims were less likely to Utilized UPHCC.

Conclusion: Apart from the entitlement card, other factors such as monthly income BDT> 10,000, small family size, no formal educated mother appeared to be potential predictors for utilization of the Urban Primary Health care clinic.

Keywords: entitlement card, maternal care, Utilization, urban primary healthcare
Correspondence:
Md Mizanur Rahman. Department of Community Medicine and Public Health, Faculty of Medicine and Health Sciences, Universiti Malaysia Sa- rawak.Email:rmmizanur@unimas.my, rmizanu- r1958@gmail.com.

Cite this as:

Mizan S, Rahman MM, Safii R, Ahmad SA (2020). Does Entitlement Card ensure utilization of Urban Primary Healthcare Clinic in Bangladesh? J Matern Child Health. 5(2): 213-225.

https://doi.org/10.26911/thejmch.2020.05.02.12

\section{Journal of Maternal and Child Health is licensed under a Creative Commons} Attribution-Non Commercial-Share Alike 4.0 International License.

\section{BACKGROUND}

The eight elements of Primary Health Care (PHC) are rendered since the inception in 1979-1980 of PHC services in Bangladesh. The Government of Bangladesh, since 1998, has been pursuing a Sector-Wide Ap- proach (SWAp). Based on the previous SWAps, the Ministry of Health and Family Welfare (MOHFW) has prepared the $4^{\text {th }}$ SWAp (2017-22) which would serve as the first and the foundation stone of three subsequent SWAps. The primary health care 
service provision operates at three tiers, i.e., Upazilla, union and the community linking them with the districts as part of the publicsector health service which is rural-based infrastructure (Ministry of Health and Family Welfare, 2017).

But in urban areas, delivery of preventive health services including Primary Health Care services is mandated to the Ministry of Local Government, Rural Development and Cooperatives (Ahmed et al., 2015).

For a while, there has been proportionnately less investment in the primary health care services for the urban poor and slum dwellers to meet these priority needs. The delivery of preventive health and limited curative care as an obligation of the city corporations and municipalities under the provision of Municipal Administration Ordinance of 1960, the Pourashova Ordinance of 1977, the City Corporation Ordinance of 1983 and the Local Government (Pourashova) Act 2009.

The Urban Primary Health Care Project (UPHCP) was introduced with the support from Development partners, Donor agency and Bangladesh Government. A PrivatePublic Partnership (PPP) model was adopted to provide primary health care services and in particular maternal and child health services to the urban poor. Urban Primary Health Care Project (UPHCP) is also providing Essential Service Delivery plus package through three tires as Comprehensive Reproductive Health Care Centers (CRHCCs), PHCCs and satellite clinics in selected partnership areas (Local Government Division, Bangladesh, 2012).

Direct obstetric complications cause the majority of maternal deaths and disabilities. These deaths and morbidities would be avoided if women can get timely and ample antenatal, delivery, and post-delivery services. The dropping of maternal morbidities and mortalities is the global issue that is given due attention by the government of countries worldwide (Zelalem-Ayele et al., 2014). Banke-Thomas et al. (2017) reported understanding better the maternal health service utilization pattern of the pregnant adolescent in low and middle-income countries. They found minimal research has been done in these vulnerable areas while more common significant factors were wealth quintile, media exposure and rural/urban residence.

The education of the mother and her partner were the commonest significant factors that influenced utilization. Antenatal care utilization predicted the use of skilled birth attendance and the use of both predicted use of postnatal care. In Bangladesh, the central policy focus since the late $1990 \mathrm{~s}$ was the reduction of maternal mortality and the extension of safe motherhood services. This was reflected in the Health and Population Sector Strategy (HPSS) and the rights' based National Policy for Maternal Health of 2001. An Essential Services Package (ESP) including comprehensive services for antenatal, delivery and post-delivery and neonatal care at primary level healthcare facilities throughout the country, has been treated as a central program feature (Ministry of Health and Family Welfare, 2017).

The UPHCP is providing a package of high-impact primary healthcare services to the urban population, mainly targeting the poor women and children in urban areas of Bangladesh with entitlement cards, popularly known as 'red card'. A red cardholder is allowed access to all types of care at urban primary healthcare centers free of costs. To identify the beneficiaries of a red card, a baseline survey was conducted by the partner NGOs at the beginning of the partnership agreement to identify poor households in the respective partnership areas. Poor families were identified based on the project prescribed social and economic indicators. These 
households were given entitlement health cards giving them free access to health services under the project. The survey of lowincome families would be updated annually (Local Government Division, Bangladesh, 2012). There are some other health cards available in Bangladesh some of which are Green Color and Orange Color. In earlier Smiling Sun Clinic had implemented the Urban Family Health Partnership health card scheme.

This scheme comprised three types of health cards - Red cards for family members, Yellow cards for the middle class and Green cards for extremely poor, which are not currently available. Then the NGO Service Delivery Program (NSDP) had modified earlier schemes and introduced Health Benefit Cards (HBCs) scheme. Under this scheme Smiling Sun Clinic has been implemented partially or fully following two cards - Green Color Health Benefits Card for Least Advantaged (LA) people and Orange Color Health Benefits Card for the middle and upper-middle class (able to pay customer) (HB Consultants and Natural Resources Planners, 2012).

Considering this view, this study was aimed to estimate the proportion of urban women utilizing the urban healthcare clinic for their maternal care and the factors affecting it. However, the study was aimed to determine to what extent an entitlement card influences them to utilize the urban primary health care clinic.

\section{SUBJECTS AND METHOD}

\section{Study design}

This was a cross-sectional study conducted in working areas of Urban Primary Healthcare Project (UPHCP) areas in seven divisions of Bangladesh.

\section{Population and sample}

A two-stage cluster sampling technique was adopted to select the ever-married women aged 15-49 years having at least one child aged within two years. For the determination of sample size, the anticipated population proportion of urban poor was considered as base criteria with $10 \%$ relative precision and 95\% confidence interval.

The initial sample size was 896 which then inflated by multiplying non-response, design effect. So, the final sample size was 4124. However, 3949 completed questionnaires were collected with a response rate of 95.8\%. The respondents who did not consent or unwilling to participate, visitors, or guests residing in the household were excluded from the study.

\section{Study Variables}

The dependent variable was the utilization of maternal care services from urban primary health care clinics. The independent variables were having an entitlement card, catchment area, age of the respondent, religion, family size, level of education of the respondent, occupation of the husband and respondent, wealth index and ownership status of the house.

\section{Operational Definition of Variables} The utilization of maternal and child health refers to antenatal care, delivery care, post-natal care and family planning. For child health, vaccination, ARI, diarrhea, fever and child nutrition was assessed.

Wealth index is a composite measure of a household's cumulative living standard. The wealth index is calculated using easy-to-collect data on a household's ownership of selected assets, such as televisions and bicycles; materials used for housing construction, and types of water access and sanitation facilities. Catchment area was defined as the set rules or criteria provided by the Ministry of Local Government to classy the area into Poor and non-poor.

Entitlement card is a red color document given by the project authority which verifies the bearer's eligibility for a particular service from the project UPHC clinic. 
Mizan et al./ Does Entitlement Card ensure Utilization of Urban Primary Health Care in Bangladesh?

\section{Study Instrument}

The questionnaire was divided into five parts. The first section was the socioeconomic and demographic characteristics followed by utilization of $\mathrm{MCH}$ services. In the present paper, we analyzed the usage of maternal care in terms of antenatal, delivery, and postnatal care (Rahman, 1997; National Institute of Population Research and Training, Bangladesh, 2012).

Before field operation, the pre-test of the questionnaire was done in the non-sample area. Data were collected through face-toface interviews using the interviewer-administered questionnaire. Failure to respond after three attempts of the interview was considered as non-response.

\section{Data analysis}

A completed data was entered into the computer for analysis. Incomplete and inaccurate and missing information in the main components of the questionnaire was discarded. Before data analysis, data were cross-checked for any unusual findings, outliers and missing values (Sterne et al., 2009). Descriptive statistics were presented in frequency, percentage, mean and standard deviation. For inferential statistics, Chi-square test of independence was done to find a significant association between the qualitative variables.

To determine the utilization of maternal care, a question was asked whether the respondents received antennal care, delivery and post-natal care in her last pregnancy. Then she was asked for the place of the utilization of care. If she received service from UPHCC then it was coded as ' 1 ' and others were coded as ' $O$ '. A composite score was calculated with three as full utilization, 1 and 2 as partial and zero as non-utilization of UPHCC. Finally, a stepwise multinomial logistic regression analysis was done to determine the factors associated with the utilization of maternal care from UPHCC. Statisti- cal analysis was done using Statistical Package SPSS, version 22.0 (IBM SPSS, 2013).

\section{Research ethics}

The Ethical Committee of Universiti Malaysia Sarawak (UNIMAS) has approved this study (UNIMAS/NC-21.02/03-02.JID.02 (08), 11 February 2014). Ethical approval was also obtained from the Bangladesh Medical Research Council (BMRC), Bangladesh (BMRC/NREC-2013-2016/1265, 30 June 2015). All the respondents were briefed about the objectives of the study and written informed consent was obtained before data collection.

\section{RESULTS}

\section{Sociodemographic characteristics}

The details of socio-demographic characteristics are illustrated in Table 1 . This study attempted to calculate the wealth index based on household assets i.e. usable goods and avoiding assessing the income of the households. In Urban Primary Healthcare Project (UPHCP) working area, entitlement cards (red card) were issued to the poor families to avail healthcare services free of charge from UPHCP facilities. Out of 3949 respondents, 20\% entitlement cardholder had shown there to the interviewer. However, another $5 \%$ did not show a card, although they claimed to have a card.

\section{Utilization of maternal care}

Out of 3949 respondents, $7.2 \%$ did not receive any antenatal care; however, those who received antenatal care, $51.5 \%$ from nonUPHCC and $48.5 \%$ from UPHCC. In terms of delivery care, $70.4 \%$ received delivery care from other than UPHCC, and only $29.6 \%$ received delivery care from UPHCC. The prevalence of postnatal care was less than antenatal care and $\mathbf{2 2 . 8 \%}$ did not receive postnatal care. Half of the respondents received postnatal care from non-UPHCC and the rest were from UPHCC (Figure 1). 
Mizan et al./ Does Entitlement Card ensure Utilization of Urban Primary Health Care in Bangladesh?

Table 1. Sociodemographic characteristics

\begin{tabular}{|c|c|c|}
\hline Characteristics & Frequency & $\%$ \\
\hline \multicolumn{3}{|c|}{ Type of catchment area } \\
\hline Non-poor & 1985 & 50.3 \\
\hline Poor & 1964 & 49.7 \\
\hline \multicolumn{3}{|l|}{ Age (Years) } \\
\hline$<20$ & 302 & 7.6 \\
\hline $20-24$ & 1461 & 37.0 \\
\hline $25-29$ & 1304 & 33.0 \\
\hline $30-34$ & 565 & 14.3 \\
\hline $35-39$ & 261 & 6.6 \\
\hline$\geq 40$ & 56 & 1.4 \\
\hline \multicolumn{3}{|l|}{ Religion } \\
\hline Non-Muslim & 380 & 9.6 \\
\hline Muslim & 3569 & 90.4 \\
\hline \multicolumn{3}{|l|}{ Family Size } \\
\hline$<4$ & 864 & 21.9 \\
\hline 4 & 1221 & 30.9 \\
\hline 5 & 936 & 23.7 \\
\hline$\geq 6$ & 928 & 23.5 \\
\hline \multicolumn{3}{|l|}{ Level of education } \\
\hline No formal education & 456 & 11.5 \\
\hline Primary School & 1509 & 38.2 \\
\hline Secondary School & 1263 & 32.0 \\
\hline Higher Secondary & 456 & 11.5 \\
\hline Graduate and above & 265 & 6.7 \\
\hline \multicolumn{3}{|c|}{ Occupation (respondents) } \\
\hline Not working & 192 & 4.9 \\
\hline Working & 475 & 12.0 \\
\hline Housewife & 3282 & 83.1 \\
\hline \multicolumn{3}{|c|}{ Occupation (Husband) } \\
\hline Small trade & 1078 & $27 \cdot 3$ \\
\hline Service & 968 & 24.5 \\
\hline Manual job & 1760 & 44.6 \\
\hline No specific job & 143 & 3.6 \\
\hline \multicolumn{3}{|c|}{ Having entitlement card } \\
\hline Yes & 988 & 25.0 \\
\hline No & 2961 & 75.0 \\
\hline \multicolumn{3}{|l|}{ Wealth index } \\
\hline Poorest & 776 & 19.7 \\
\hline Poor & 828 & 21.0 \\
\hline Middle class & 767 & 19.4 \\
\hline Rich & 786 & 19.9 \\
\hline Richest & 792 & 20.1 \\
\hline \multicolumn{3}{|l|}{ Ownership status } \\
\hline Own & 1592 & 40.3 \\
\hline Rented & 1998 & 50.6 \\
\hline Sheltered & 359 & 9.1 \\
\hline
\end{tabular}

Comparative analysis revealed that utilization of urban primary healthcare project clinic was found to be high among the respondents from the poor catchment area in terms of ANC (59.0\%), delivery care (36.4\%) and postnatal care (62.4\%). Whereas the respon- dents from the non-poor catchment area mostly received services from the non-UPHC clinic and the difference was statistically significant ( $\mathrm{p}<0.001)$. However, their strength of association (effect size) was small (Table 2). 
Mizan et al./ Does Entitlement Card ensure Utilization of Urban Primary Health Care in Bangladesh?

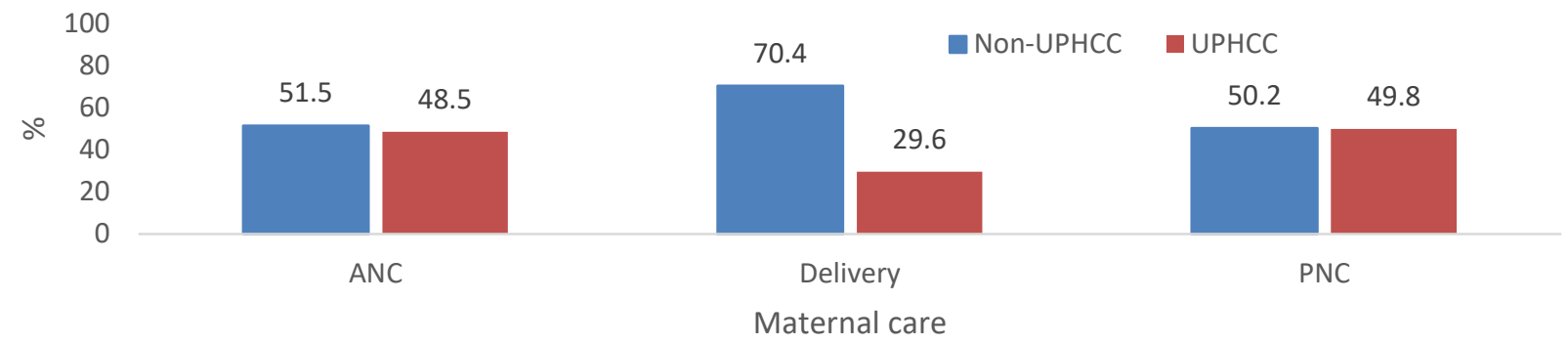

Figure 1 Percentage distribution of respondents by maternal care

Table 2. Utilization of urban primary healthcare clinic by the catchment area

\begin{tabular}{|c|c|c|c|c|c|}
\hline \multirow[t]{3}{*}{ Place of service } & \multicolumn{4}{|c|}{ Catchment area } & \multirow{3}{*}{$\begin{array}{c}\mathbf{p} \\
(\mathbf{E S})\end{array}$} \\
\hline & \multicolumn{2}{|c|}{ Non-poor } & \multicolumn{2}{|c|}{ Poor } & \\
\hline & $\mathbf{n}$ & $\%$ & $\mathbf{n}$ & \% & \\
\hline \multicolumn{6}{|l|}{ Place of ANC } \\
\hline Non-UPHCC & 1151 & 61.6 & 733 & 41.0 & \multirow{2}{*}{$\begin{array}{r}<\mathbf{0 . 0 0 1} 1 \\
(0.202\end{array}$} \\
\hline UPHCC & 718 & 38.4 & 1055 & 59.0 & \\
\hline \multicolumn{6}{|l|}{ Place of delivery } \\
\hline Non-UPHCC & 1532 & 77.2 & 1250 & 63.6 & \multirow{2}{*}{$\begin{array}{c}<\text { o.001 } \\
(0.15)\end{array}$} \\
\hline UPHCC & 453 & 22.8 & 714 & 36.4 & \\
\hline \multicolumn{6}{|l|}{ Place of PNC } \\
\hline Non-UPHCP & 976 & 61.6 & 554 & 37.9 & \multirow{2}{*}{$\begin{array}{c}<\mathbf{0 . 0 0 1} \\
(0.23)\end{array}$} \\
\hline UPHCP & 608 & 38.4 & 909 & 62.1 & \\
\hline \multicolumn{6}{|c|}{$\begin{array}{l}\text { Overall Utilization } \\
\text { of UPHCC }\end{array}$} \\
\hline No & 1167 & 58.8 & 812 & 41.3 & \multirow{3}{*}{$\begin{array}{c}<\mathbf{0 . 0 0 1} \\
(0.18)\end{array}$} \\
\hline Partial & 421 & 21.2 & 500 & $25 \cdot 5$ & \\
\hline Fully & 397 & 20.0 & 652 & 33.2 & \\
\hline
\end{tabular}

${ }^{*} \mathrm{p}<0.05,{ }^{* *} \mathrm{p}<0.01,{ }^{* * *} \mathrm{p}<0.001$

${ }^{*} \mathrm{p}$-value reached from chi-square test, $\mathrm{ES}=\mathrm{Effect}$ size

2. Factor affecting the overall Utilization of maternal care from UPHCC: Multinomial logistic regression analysis

To determine the factors affecting the utilization of maternal care, a stepwise multinomial logistic regression analysis was done, as the dependent variable was the overall utilization of maternal care, which was categorized into fully, partial and non-utilization of UPHCC. The non-utilization of UPHCC was considered as the reference. All the sociodemographic variables such as religion, level of education, the occupation of the respondents and husband, history of borrow loan, having an entitlement card, wealth index, age in years were included into the model. However, religion, level of education, monthly household income, family size, having an entitlement card, and age in years retained in the model.

The model information indicated that the chi-square (df) was 1004.135(26); p $<0.001)$ and the goodness of fit (GOF) was not statistically significant ( $p>0.05$ ) indicating well-fitted model with homogeneity. 
Mizan et al./ Does Entitlement Card ensure Utilization of Urban Primary Health Care in Bangladesh?

Table 3 Factors affecting the Utilization of maternal care services from urban primary health care clinic

\begin{tabular}{|c|c|c|c|c|c|c|c|c|c|c|}
\hline \multirow{3}{*}{ Parameters } & \multicolumn{5}{|c|}{ Partially } & \multicolumn{5}{|c|}{ Fully } \\
\hline & \multirow{2}{*}{$\boldsymbol{\beta}$} & \multirow{2}{*}{$\mathbf{S E}$} & \multirow{2}{*}{ OR } & \multicolumn{2}{|c|}{$95 \% \mathrm{CI}$} & \multirow{2}{*}{$\boldsymbol{\beta}$} & \multirow{2}{*}{$\mathbf{S E}$} & \multirow{2}{*}{ AOR } & \multicolumn{2}{|c|}{$95 \% \mathrm{CI}$} \\
\hline & & & & $\mathbf{L L}$ & $\mathbf{U L}$ & & & & $\mathbf{L L}$ & UL \\
\hline \multirow[t]{2}{*}{ Intercept } & - & $\mathrm{O}$ & & & & - & that & & & \\
\hline & $2.25^{* * *}$ & .33 & & & & $4.15^{* * *}$ & .34 & & & \\
\hline \multicolumn{11}{|l|}{ Religion } \\
\hline Non-Muslim & $-0.54^{* * *}$ & 0.15 & 0.59 & 0.44 & 0.78 & $-0.80^{* * *}$ & 0.17 & 0.45 & 0.32 & 0.63 \\
\hline Muslim (RC) & & & 1.00 & & & & & 1.00 & & \\
\hline \multicolumn{11}{|l|}{ Level of education } \\
\hline No formal education & $0.57^{* *}$ & 0.23 & 1.76 & 1.12 & 2.77 & $0.84^{* * *}$ & 0.24 & 2.32 & 1.46 & 3.68 \\
\hline Primary School & $1.00^{* * *}$ & 0.20 & 2.71 & 1.82 & 4.04 & $1.12^{* * *}$ & 0.21 & 3.08 & 2.03 & 4.67 \\
\hline Secondary School & $0.60^{* * *}$ & 0.20 & 1.82 & 1.23 & 2.68 & $0.55^{* *}$ & 0.21 & 1.72 & 1.14 & 2.60 \\
\hline Higher Secondary & 0.12 & 0.23 & 1.13 & 0.72 & 1.76 & 0.35 & 0.23 & 1.42 & 0.90 & 2.25 \\
\hline $\begin{array}{l}\text { Graduate and above } \\
\text { (RC) }\end{array}$ & & & 1.00 & & & & & 1.00 & & \\
\hline \multicolumn{11}{|l|}{ Family size } \\
\hline$<4$ & 0.03 & 0.13 & 1.03 & 0.81 & 1.32 & $0.55^{* * *}$ & 0.14 & 1.73 & 1.32 & 2.26 \\
\hline 4 & 0.15 & 0.11 & 1.17 & 0.93 & 1.45 & $0.49^{* * *}$ & 0.12 & 1.64 & 1.29 & 2.08 \\
\hline 5 & -0.12 & 0.12 & 0.88 & 0.70 & 1.12 & 0.23 & 0.13 & 1.26 & 0.98 & 1.63 \\
\hline$\geq 6(\mathrm{RC})$ & & & 1.00 & & & & & 1.00 & & \\
\hline \multicolumn{11}{|c|}{ Having an entitlement card } \\
\hline Yes & $1.29^{* * *}$ & 0.11 & 3.64 & 2.91 & 4.56 & $2.46^{* * *}$ & 0.11 & 11.75 & 9.48 & 14.55 \\
\hline No (RC) & & & 1.00 & & & & & 1.00 & & \\
\hline \multicolumn{11}{|l|}{ Family income (BDT) } \\
\hline$<10000.0$ & 0.29 & 0.15 & 1.34 & 1.00 & 1.81 & 0.09 & 0.15 & 1.09 & 0.81 & 1.48 \\
\hline 10000.0 - 19999.9 & $0.53^{* * *}$ & 0.14 & 1.70 & 1.29 & 2.24 & 0.04 & 0.15 & 1.04 & 0.78 & 1.39 \\
\hline $20000.0-29999.9$ & $0.35^{*}$ & 0.16 & 1.42 & 1.04 & 1.93 & 0.25 & 0.16 & 1.28 & 0.93 & 1.77 \\
\hline$\geq 30000(\mathrm{RC})$ & & & 1.00 & & & & & 1.00 & & \\
\hline Age in years & 0.01 & 0.01 & 1.01 & 1.00 & 1.03 & $0.07^{* * *}$ & 0.01 & 1.07 & 1.05 & 1.09 \\
\hline n observation & 3,949 & & & & & & & & & \\
\hline Model Chi ${ }^{2}$ (df) & \multicolumn{10}{|c|}{$1004.135(26) ; \mathrm{p}<0.001$} \\
\hline Pearson & \multicolumn{10}{|c|}{ 4776.888(4638); $\mathrm{p}>0.05$} \\
\hline Deviance & \multicolumn{10}{|c|}{$4602.864(4638) ; p>0.05$} \\
\hline Cox and Snell & \multicolumn{10}{|l|}{$22.5 \%$} \\
\hline Nagelkerke & \multicolumn{10}{|l|}{$25.7 \%$} \\
\hline McFadden & \multicolumn{10}{|l|}{0.122} \\
\hline Reference & \multicolumn{10}{|c|}{ Non-utilization of UPHCC } \\
\hline Classification & \multicolumn{10}{|l|}{$60 \%$} \\
\hline
\end{tabular}

Dependent variable: utilization of UPHCC (None, partial and fully)

The Pseudo Cox and Snell R²= 22.5\%; Nagelkerke $=25.7 \%$. Predicted classification showed that $60 \%$ correctly classify the dependent variable. The analysis revealed that the nonMuslim were $46 \%$ less likely to partially utili- zed the UPHCC, and 20\% less likely to utilize fully. It was found that respondents who had no formal education, 2.32 times (95\% CI= 1.46 to $3.68, \mathrm{p}=0.001$ ) likely to fully utilized UPHCC, whereas, 1.76 times (95\% CI= 1.12 to 
Mizan et al./ Does Entitlement Card ensure Utilization of Urban Primary Health Care in Bangladesh?

2.77; $\mathrm{p}=0.004$ ) likely to partially utilized UPHCC. Among the respondents with a primary level of education, 2.71 times (95\% CI= 1.82 to $4.04 ; \mathrm{p}=0.018$ ) likely to utilized partially and 3.08 times $(95 \% \mathrm{CI}=2.03$ to $4.67 ; \mathrm{p}=$ o.001) fully utilized the UPHCC.

However, the secondary level of education, 1.82 times $(95 \% \mathrm{CI}=1.25$ to 2.68 ; $\mathrm{p}=$ $0.004)$ partially and 1.72 times $(95 \% \mathrm{CI}=1.14$ to $2.60 ; p=0.017$ ) likely to fully utilized the clinic. Those who had entitlement card, 11.75 times (95\% CI= 9.48 to $14.55 ; \mathrm{p}=0.001$ ) likely to fully utilized UPHCC and 3.64 times (95\% $\mathrm{CI}=2.91$ to $4.56 ; \mathrm{p}=0.001$ ) likely to partially utilized UPHCC.

The monthly income BDT 10,000$19,999,1.70$ times likely ( $95 \% \mathrm{CI}=1.29$ to 2.24; $\mathrm{p}=0.001$ ) to partially utilized UPHCC. However, other income categories had no impact on utilization. The family size with less than four members were 1.73 times $(95 \% \mathrm{CI}=$ 1.32 to $2.26 ; \mathrm{p}=0.010$ ) and family size with four members were 1.64 times $(95 \% \mathrm{CI}=1.29$ to $2.08 ; \mathrm{p}=0.001$ ) likely to fully utilized UPHCC. It was found that one-unit increase of age affects 1.07 times (95\% CI $=1.05$ to 1.09; $\mathrm{p}=0.001$ ) likely to increase the utilization of UPHCC (Table 3).

\section{DISCUSSION}

Majority of respondents in this study received their last ANC from the doctor. This result is higher than other studies in UPHCP-II (HB Consultants and Natural Resources Planners, 2012; Research Evaluation Associates for Development, 2012). Respondents having an entitlement card were more likely to utilized urban primary health care clinic than without card.

In a past study of UPHCP-II revealed that most of the entitlement cardholders received health care services with satisfaction due to free services, free medicine and availability of care which support the present finding. This study found that $29.6 \%$ of women delivered their last child at UPHCP clinic. In another study of UPHCP, results of the present study are almost similar to their findings where delivery at UPHCP was $28.5 \%$ (HB Consultants and Natural Resources Planners, 2012).

Here, most of the respondents received PNC from medically trained personnel which is higher than several studies in Bangladesh. More than two-fifths of the women received their first follow-up check after delivery within one day (45.8\%). Findings are similar to BDHS, 2014 results (National Institute of Population Research and Training, Bangladesh, 2016), and higher than other survey reports in Bangladesh (HB Consultants and Natural Resources Planners, 2012; National Institute of Population Research and Training, Bangladesh, 2013; Research Evaluation Associates for Development, 2012).

This study found that the age of the mother appeared to be an independent predictor for utilization of institutional care. Mothers with older age were likely to fully utilized urban primary health care clinic. This might be due to their previous experience, guiding them to choose institutional care. However, other than UPHCC, the receiving maternal care among the young mother was satisfactory. This might be the fact that UPHCC is mostly providing basic health care compared to specialized medical care facilities.

Weldemariam et al. (2018) reported that younger women were more likely to utilized institutional care. Similar studies reported that young mothers were more likely to utilize institutional care (Amano et al., 2012; Teferra et al., 2012; Wolelie et al., 2014). Though the religious beliefs in modern medicine are not always taken into consideration, however, sometimes, seeking any related medical services can use their beliefs to guide them to select the health services (Eisenhut, 2018). The present study revealed that non- 
Muslim were less likely to utilized urban healthcare project clinic. This might be due to the fact that Bangladesh is Muslim dominant countries with $92 \%$ Muslims. Similar findings were reported in past studies with an association between service utilization and religion (Addai, 2000; Gyimah et al., 2006).

They contradicted the findings of our study and indicated that Muslim women are less likely to utilize postnatal services. The result of their study shows that Christian women had higher utilization of this service. This may be due to the strong link between Christianity and medicine. Bangladesh has a comprehensive network of health service delivery from top to grass root level. To ensure the optimum health to the poor, the government of Bangladesh implemented the Essential Service Package (ESP) which ensure the basic Medicare to all especially the poor (Ministry of Health and Family Welfare, Bangladesh, 1998).

However, these services were mostly implemented through primary healthcare services in the sub-district and below level. The same concept was also implanted in urban areas. The only difference is that it is implemented through the local government of Bangladesh. Ahmed et al. (2006) reported that the targeted intervention among the ultra-poor in rural areas increases the accessibility of health care services, especially Allopathic Medicare.

Our study had similar finding with the distribution of entitlement card increase in the healthcare services in terms of preventive, promotive and curative care from the urban healthcare clinic. Though the delivery cares are less than the national expectation, it has an increase in trend. In our study, it was found that the level of education had an impact on utilization of reproductive health care. These findings indicated that with formal education, primary and secondary level of education increases the likelihood of maternal care from the UPHCC. However, beyond the secondary level of education, it had no impact. This might be the fact that the healthcare services are especially targeted for the urban poor. With increasing level of education, they had the preference to take care from specialized health care services.

The level of education grounded the transformative role in improving the health of the individual and also to the society, i.e. education helps to develop their capacity to personal control, mastery, and self-direction: the habits and skills of communication and analytic skills (Ivančič et al., 2008).

Kim (2016) argued that educated women are more physically capable of procuring child than the uneducated, but want fewer children and control birth better. This decrease family size. Nonetheless, educated women provide better care at home, thus increasing the value of their children's human capital and reducing the need for more children. This might be a link that the educated women with a small family size increase the utilization of health care service. In our study, the pattern of utilization was likely to be the same with others studies (Kifle et al., 2017; Srivastava et al., 2014; Zhang et al., 2016).

Respondents are having health entitlement card or red card likely to be fully and partially utilized $\mathrm{MCH}$ care from UPHCP more than respondents having no entitlement card in this study. Health entitlement card, popularly known as a red card since it is red is an essence of the UPHCP. It is like a free ticket for the urban poor, marginalized dwellers to visit UPHCP health facility to get treatment at free of cost. There were few studies in UPHCP which also showed similar findings (HB Consultants and Natural Resources Planners, 2012; National Institute of Population Research and Training, Bangladesh, 2013; Research Evaluation Associates for Development, 2012). 
Other than the red card of this project, the government of Bangladesh with support from development partners have introduced different healthcare schemes for the poor and marginalized people for improving maternal health situation examples are Demand Side Financing (DSF)-Voucher schemes introduced by MOHFW and voucher schemes by Marie Stopes Clinic Society (World Health Organization, 2010).

Maximum past studies opined that the DSF-MHVS has ominously enhanced access to maternal health services for the voucher holders and utilization of ANC, safe delivery and PNC have increased in the DSF areas and among voucher holders (Ahmed and Khan, 2011; Farzana, 2014; Halim, 2014; Hatt et al., 2010; Noor et al., 2013). In the DSF areas, equity in maternal health service utilization has also improved compared to similar nonDSF areas. Although one study did not find any effect on equity, income, especially low income influenced the utilization of UPHCP as it served to lowest quintile people with subsidy and free of cost. Wealth status and income, age and education affect maternal healthcare utilization(Birmeta et al., 2013; Ononokpono and Odimegwu, 2014; Rutaremwa et al., 2015). Use of maternal services is affected by socioeconomic status and has a positive relationship with the utilization of maternal care (Bernard et al., 2017; Khanal et al., 2014).

Although the majority of urban women received antenatal care (92.6\%), the utilization of antenatal care services from urban primary healthcare clinic was only $48.5 \%$. Similarly, $77.15 \%$ of the women received postnatal care, but only $49.8 \%$ were from UPHCC. The delivery was lowest (29.6\%) from UPHCC. This study revealed that age, family income, family size, level of education, religion and having entitlement card were associated with utilization of urban primary health care clinic. These findings should be taken into consideration when designing programs aimed at promoting the usage of urban primary health care clinic. These findings have important policy implications for meeting the Sustainable Development Goals (SDGs) of improving maternal health by reducing the maternal mortality. Health promotion program should be undertaken to enhance women's awareness of the utilization of urban healthcare clinic which is specially provided for the urban poor. Local Government with collaboration with the ministry of health, should initiate to implement the program.

Though the study adopted multistage cluster sampling, some limitation of this study was encountered. Most of the responses were recorded based on their memory, where recall bias might be the main issues. The data were collected from urban areas, which might not be reflected in the general population. Thus, the generalization of the results should be cautiously interpreted.

AUTHOR CONTRIBUTION
Md Mizanur Rahman and Sharmin Mizan de-
veloped the concept, design, analysis, inter-
pretation of data and manuscript writing of
the study, Sharmin Mizan and Sk Akhtar
Ahmad organized and collected data. All
authors assisted in the editing and refining of
the manuscript. All authors read and ap-
proved the final manuscript.

\section{CONFLICT OF INTEREST}

The authors declare that they have no competing interests.

\section{FUNDING AND SPONSORSHIP}

This study was funded by USAID's Next Generation of Public Health Experts (NGPHE) PhD Scholarship Program under BRAC University with partial financial support from USAID Bangladesh to promote women's leadership in public health. 
Mizan et al./ Does Entitlement Card ensure Utilization of Urban Primary Health Care in Bangladesh?

\section{ACKNOWLEDGMENT}

We are grateful to the ethics committee of Universiti Malaysia Sarawak and Bangladesh Medical Research Council, Bangladesh for ethical approval. We are very grateful to the local non-governments organization for their support in selecting the clinic area and identification of respondents through the development of the sampling frame. Thanks to all research assistants who were involved in data collection. Finally, our gratitude goes to all study participants who shared their experience during delivery care.

\section{REFERENCE}

Addai I (2000). Determinants of use of maternal-child health services in rural Ghana. J. Biosoc. Sci. 32: 1-15. Retrieved from https://www.ncbi.nlm.nih.gov/pubmed/10676056

Ahmed S, Khan MM (2011). A maternal health voucher scheme: what have we learned from the demand-side financing scheme in Bangladesh? Health Policy Plan. 26: 25-32. https://doi.org/10.1093/heapol/czq015

Ahmed SM, Alam BB, Anwar I, Begum T, Rumana H, Khan JA, Nababan H, Osman FA (2015). Bangladesh health system review. Geneva: World Health Organization.

Ahmed SM, Petzold M, Kabir ZN, Tomson G (2006). Targeted intervention for the ultra-poor in rural Bangladesh: Does it make any difference in their healthseeking behavior? Soc. Sci. Med. 63: 2899-2911. https://doi.org/10.1016/j.socscimed.2006.07.024

Amano A, Gebeyehu A, Birhanu Z (2012). Institutional delivery service utilization in Munisa Woreda, South East Ethiopia: a community-based cross-sectional study. BMC Pregnancy Childbirth 12: 105. https://doi.org/10.1186/1471-2393-12-105
Banke-Thomas OE, Banke-Thomas AO, Ameh CA (2017). Factors influencing utilization of maternal health services by adolescent mothers in Low-and middle-income countries: a systematic review. BMC Pregnancy Childbirth 17: 65. https://doi.org/10.1186/s12884-0171246-3

Bernard HR, Wutich A, Ryan GW (2017). Analyzing Qualitative Data: Systematic Approaches, Second edition. ed. USA: SAGE Publications Pvt. Ltd.

Birmeta K, Dibaba Y, Woldeyohannes D (2013). Determinants of maternal health care utilization in Holeta town, central Ethiopia. BMC Health Serv. Res. 13: 256. https://doi.org/10.1186/1472-6963-13-256

Eisenhut A (2018). Cultural Connection: The Impact of Religion Can Play in Health care.

Farzana S (2014). Demand Side Financing (DSF) - Maternal Health Voucher Scheme in Bangladesh. https://doi.org/10.1186/s12884-017-1445-y

Gyimah SO, Takyi BK, Addai I (2006). Challenges to the reproductive-health needs of African women: on religion and maternal health utilization in Ghana. Soc. Sci. Med. 1982 62, 2930-2944. https://doi.org/10.1016/j.socscimed.20 05.11.034

Halim MA (2014). An Analysis of Facilitybased Exit Interview with the Maternal Voucher Recipients under Demand Side Financing Initiative in Bangladesh. Dhaka. Dhaka, Bangladesh. Retrieved from http://spfmsp.org/wp-content/uploads/2017/01/2017-01-10-DSF-

Final-Report.pdf

Hatt L, Nguyen H, Sloan N, Miner S, Magvanjav O, Sharma A, Chowdhury J, et al. (2010). Economic Evaluation of Demand-Side Financing (DSF) for Maternal Health in Bangladesh. Retrieved 
Mizan et al./ Does Entitlement Card ensure Utilization of Urban Primary Health Care in Bangladesh?

from https://reliefweb.int/sites/reliefweb.int/files/resources/Bangladesh\%2 oDSF\%20evaluation_FINAL_Feb\%20 2010.pdf

HB Consultants and Natural Resources Planners (2012). Assessing the impact of user fees on UPHC-Reviewing health voucher and user fees exemptions. Second Urban Primary Health Care Project. Retrieved from https://www.adb.org/sites/default/files/project-document/73917/42177-013-ban-pam.pdf

IBM SPSS (2013). IBM SPSS Statistics for Windows. New York, USA: IBM SPSS, Armonk.

Ivančič A, Mirčeva J, Vrečer N (2008). Literature Review Report: Impact of education on health (youth, women, people with disabilities). Retrieved from https://arhiv.acs.si/porocila/Impact_o f_education_on_health.pdf

Khanal V, Adhikari M, Karkee R, Gavidia T (2014). Factors associated with the utilization of postnatal care services among the mothers of Nepal: analysis of Nepal demographic and health survey 2011. BMC Women's Health 14: 19. https://doi.org/10.1186/1472-6874-1419

Kifle D, Azale T, Gelaw YA, Melsew YA (2017). Maternal health care service seeking behaviours and associated factors among women in rural Haramaya District, Eastern Ethiopia: a triangulated community-based cross-sectional study. Reprod. Health 14. https://doi.org/10.1186/s12978-016-0270-5

Kim J (2016). Female education and its impact on fertility. IZA World Labor 1-10. https://doi.org/10.15185/izawol.228

Local Government Division, Bangladesh (2012). Design Project Proforma (DPP): Urban Primary Health Care Services Delivery Project, Bangladesh, 2012. Ministry of Local Government, Rural
Development and Co-operatives, Dhaka, Bangladesh.

Ministry of Health and Family Welfare (2017). $4^{\text {th }}$ Health, Population and Nutrition Sector Programme ( $4^{\text {th }}$ HPNSP), January 2017- June 2022. Programme Implementation Plan (PIP). Retrieved from https://extranet.who.int/nutrition/gina/en/node/26353

Ministry of Health and Family Welfare, Bangladesh (1998). Project Implementation Plan, 1998.

National Institute of Population Research and Training, Bangladesh (2012). Bangladesh Maternal Mortality and Health Care Survey 2010 (Publication). National Institute of Population Research and Training (NIPORT), MEASURE Evaluation, and ICDDR, B, Dhaka, Bangladesh.

National Institute of Population Research and Training, Bangladesh (2013). Endline Household Survey under Second Urban Primary Health Care Project, 2012, Dhaka City Corporation. National Institute of Population Research and Training (NIPORT), Dhaka.

National Institute of Population Research and Training, Bangladesh (2016). Bangladesh Demographic and Health Survey 2014. Retrieved from https://dhsprogram.com/pubs/pdf/FR311/FR3 11.pdf

Noor FR, Talukder NM, Rob U (2013). Effect of a maternal health voucher scheme on out-of-pocket expenditure and use of delivery care services in rural Bangladesh: A prospective controlled study. The Lancet 382: 20. https://doi.org/10.1016/So140-6736(13)62181-9

Ononokpono DN, Odimegwu CO (2014). Determinants of Maternal Health Care utilization in Nigeria: a multilevel approach. Pan Afr. Med. J. 17 Suppl 1:2. https://doi.org/10.11694/pamj.supp.20 
Mizan et al./ Does Entitlement Card ensure Utilization of Urban Primary Health Care in Bangladesh?

14.17.1.3596

Rahman MM (1997). Socio-Demographic Determinants of Infant Mortality and Morbidity and Its Correlation with Maternal Health in Slum Dwellers of Dhaka City (Thesis). Dhaka University, Dhaka, Bangladesh.

Research Evaluation Associates for Development (2012). Enhancing Cost Effectiveness and Improving Quality of UPHC. Second Urban Primary Health Care Project (UPHCP-II). Local Government Division, Ministry of Local Government, Rural Development \& Cooperatives, Bangladesh, Dhaka, Bangladesh.

Rutaremwa G, Wandera SO, Jhamba T, Akiror E, Kiconco A (2015). Determinants of maternal health services utilization in Uganda. BMC Health Serv. Res. 15: 271. https://doi.org/10.1186/s12913-O15-0943-8

Srivastava A, Mahmood S, Mishra P, Shrotriya V (2014). Correlates of Maternal Health Care utilization in Rohilkhand Region, India. Ann. Med. Health Sci. Res. 4, 417-425. https://doi.org/10.4103/2141-9248.133471

Sterne JAC, White IR, Carlin JB, Spratt M, Royston P, Kenward MG, Wood AM, et al. (2009). Multiple imputations for missing data in epidemiological and clinical research: potential and pitfalls. BMJ 338, b2393. https://doi.org/10$.1136 /$ bmj.b2393

Teferra AS, Alemu FM, Woldeyohannes SM (2012). Institutional delivery service utilization and associated factors among mothers who gave birth in the last 12 months in Sekela District, North West of Ethiopia: A community - based cross-sectional study. BMC Pregnancy Childbirth 12(74). https://doi.org/101186/1471-2393-12-74

Weldemariam S, Kiros A, Welday M (2018). utilization of institutional delivery service and associated factors among mothers in North West Ethiopian. BMC Res. Notes 11, 194. https://doi.org/10.1186/s13104-018-3295-8

Wolelie A, Aychiluhm M, Awoke W (2014). Institutional delivery service utilization and associated factors in Banja District, Awie Zone, Amhara Regional State, Ethiopia. Open J. Epidemiol. 04: 3035. https://doi.org/10.4236/ojepi.2014.41006

World Health Organization (2010). Glimpses of innovations in primary health care in South-East Asia. World Health Organization, Regional Office for South-East Asia, New Delhi.

Zelalem-Ayele D, Belayihun B, Teji K, Admassu-Ayana D (2014). Factors Affecting utilization of Maternal Health Care Services in Kombolcha District, Eastern Hararghe Zone, Oromia Regional State, Eastern Ethiopia. Int. Sch. Res. Not. https://doi.org/10.1155/2014/917058

Zhang L, Xue C, Wang Y, Zhang L, Liang Y (2016). Family characteristics and the use of maternal health services: a population-based survey in Eastern China. Asia Pac. Fam. Med. 15. https://doi.org/10.1186/s12930-016-0030-2 